УДК 657 JEL M41

Пономарева Светлана Валерьевна

д-р экон. наук, ФГБОУ ВО

«Санкт-Петербургский

государственный экономический

университет», г. Санкт-Петербург

e-mail:tmguи@mail.ru

Слиняков Юрий Владимирович

д-р экон. наук, ФГБОУ ВО

«Государственный университет

управления», г. Москва

e-mail: uslin10@mail.ru

\section{Ponomareva Svetlana}

Doctor of Economic Sciences,

St. Petersburg State Economic

University, St. Petersburg

e-mail:tmguu@mail.ru

\section{Slinykov Yuri}

Doctor of Economic Sciences,

State University of Management,

Moscow

e-mail:uslin10@mail.ru

\section{УЧЕТНО-КОНТРОЛЬНАЯ СИСТЕМА ИНФОРМАЦИОННО-АНАЛИТИЧЕСКОГО ОБЕСПЕЧЕНИЯ ЦЕЛЕЙ УПРАВЛЕНИЯ: ПРИНЦИПЫ И ОСНОВЫ ЕЕ ФОРМИРОВАНИЯ}

\begin{abstract}
Аннотация: Исследованы вопросы формирования учетно-контрольной системы информационно-аналитического обеспечения целей управления. Определены принципь и основы ее формирования для тактических и стратегических ијелей управления бизнесом. При формировании стратегически ориентированных финансовых показателей базовое место занимает стоимость капитала компании. По результатам исследования сделан вывод, что разработанная учетно-контрольная система информационноаналитического обеспечения изелей управления рыночной стоимостью компании и ее бизнес-прочессами интегрируется с другими управленческими системами в режиме их параллельной автоматизации. Взаимосвязи всех формализованных систем воедино сводятся к созданию организационно-функциональной структурь управления компанией, информационной основой которой является интегрированный учет и управление качеством бизнес-процессов.

Ключевые слова: учетно-контрольная система информационно-аналитического обеспечения целей управления, бухгалтерская отчетность, управление компанией, рыночная стоимость компании, интегрированный учет и управление качеством бизнес-проиессов.
\end{abstract}

\section{ACCOUNTING AND CONTROL SYSTEM OF INFORMATION AND ANALYTICAL SUPPORT OF THE GOALS OF MANAGEMENT (UKSIAO), PRINCIPLES AND BASIS OF ITS FORMATION}

\begin{abstract}
The study of the formation of an accounting and control system for information and analytical support of management objectives is presented. The principles and foundations of its formation for the tactical and strategic objectives of business management are defined. When forming strategically oriented financial indicators, the cost of the company's capital takes the basic place. Based on the results of the study, it is concluded that the developed accounting and control system of information and analytical support of the company's market value management goals and its business processes is integrated with other management systems in the mode of their parallel automation. The interconnections of all formalized systems are reduced to the creation of an organizational and functional management structure a company whose information basis is integrated accounting and quality management of business processes.

Keywords: accounting and control system of information and analytical support of management goals, accounting, company management, market value of the company, integrated accounting and quality management of business processes.
\end{abstract}

Современные условия развития экономики предопределяют использование адекватных инструментов управления деятельностью экономических субъектов. В этом смысле управление доходами и расходами является актуальным средством управления бизнесом и повышения ее конкурентоспособности $[1 ; 4]$.

В широком смысле слова содержание учетно-контрольной системы, формируемой в компании для тактических и стратегических целей управления бизнесом, т. е. раскрытие ее функциональных характеристик на текущий финансовый год и на перспективу можно свести к научно обоснованному процессу модификации базовых показателей системы бухгалтерского учета.

Действующий план счетов бухгалтерского учета коммерческих предприятий позволяет интегрировать системы финансового и управленческого учета экономического субъекта на многовариантной основе [4; 5].

(С) Пономарева С.В., Слиняков Ю.В., 2018 
Следует полагать, что система интегрированного учета будет способствовать такому поиску, поскольку она предназначена для генерирования принципиально новых массивов информации, которые требуются для эффективного управления рыночной стоимостью компаний и их бизнес-процессами. Это предполагает, в свою очередь, отработку не только концептуальной основы такой системы, но и использование самых современных ИТ-модулей и операционных платформ, позволяющих моделировать стратегически ориентированные показатели развития бизнеса, обеспечивать транспарентность информации и конкурентоспособности компаний в новых условиях управления и хозяйствования.

Информация бюджетов по исполнению миссии компании, бухгалтерской отчетности и инструменты ее углубленного анализа демонстрирует текущее состояние компании, однако, она не дает полного представления о причинах сложившейся финансово-хозяйственной ситуации и их влиянии на стратегически ориентированные показатели. Целям получения необходимой информации для принятия управленческих решений по исправлению негативных тенденций развития бизнес-процессов служит разработанная нами учетно-контрольная система информационно-аналитического обеспечения целей управления рыночной стоимостью компании и ее бизнеспроцессов. Набор целевых показателей такой системы для оценки текущего состояния бизнеса, для выявления причин и следствий выявленных отклонений от индикаторов стратегически ориентированного планирования должны устанавливаться руководством компании и согласовываться с акционерами (собственниками). Согласованный на заседании годового собрания акционеров перечень таких показателей должен давать им исчерпывающее представление о рыночной позиции компании на каждый следующий финансовый год.

Следовательно, для экономически обоснованного определения состава и структуры целевых бизнеспоказателей, руководство компаний должно при установлении стратегического вектора развития решить целый комплекс важнейших вопросов. Во-первых, каково состояние целевого рынка и каковы на нем позиции компании. Ответ на этот вопрос предполагает постановку дополнительных вопросов: каково состояние спроса на услуги, предоставляемые компанией на рынке услуг; какова степень удовлетворения потребности заказчиков услуг компании. В случае неудовлетворительного состояния продажи услуг выявляются причины и принимаются соответствующие управленческие решения по более качественному удовлетворению заказов потребителей на услуги компании. Одним из важных управленческих решений такого плана является решение о финансовых источниках расширения ассортиментного ряда услуг, комфортности их предоставления и т. д. Параллельно решается вопрос, какого уровня финансовых результатов компания должна достичь для максимально возможного удовлетворения всех ожиданий кредиторов и акционеров.

Вторая группа вопросов сводится к поиску решения, как необходимо перестроить финансово-хозяйственные и управленческие процессы для оптимальной работы с клиентами и есть ли у компании на это технологические и финансовые возможности (ресурсы).

Третья группа вопросов касается кадровых и коммуникационно-инфраструктурных проблем. При этом необходимо решить, какие высококвалифицированные специалисты и информационные технологии необходимы для обеспечения эффективности ключевых бизнес-процессов, т. е. их ориентированности на запросы клиентов компании.

Для решения всех вышеуказанных вопросов потребуется построение системы целевого управления рыночной стоимостью компании и эффективностью всех ее бизнес процессов, которая и поименована нами как система информационно-аналитического обеспечения целей управления рыночной стоимостью компании и ее бизнес-процессов. Функционирования в компании такой системы позволяет всем ее экономическим субъектам от руководителей, акционеров до рядовых работников осознать формализованные цели развития (стратегически ориентированные показатели бюджетов) компании в целом, а также цели на уровне подразделений и коллективов сотрудников, сформулированные в соответствии с целями компании. Полной реализации всего комплекса целевых ориентиров служат детализированные стандарты бизнес-процессов, матрицы компетенций, задействованных в них работников и их ответственности за результаты деятельности. Описанные выше управленческие процедуры получили название как технологии управления по целям, в которой важной признана концепция сбалансированной системы показателей.

Информация предлагаемой нами учетно-контрольной системы информационно-аналитического обеспечения целей эффективного управления бизнесом представляет собой совокупность модифицированных данных бухгалтерского учета. Суть модификации проиллюстрирована блок-схемой на рисунке 1. В условиях нестабильного 
мирового экономического пространства и полурыночной системы в России ничего лучше не придумано как калькулирование и нормирование затрат при формировании выходных цен на товарные продукты. Ущербность российских рыночных отношений не позволит даже в среднесрочной перспективе перейти к формированию цены на основе рыночного соотношения спроса и предложения. А это означает, что затратная концепция формирования цены на товарные продукты (продукцию, работы, услуги) будет еще долго служить базой российского ценообразования. Следовательно, управление соотношением затрат и результатов экономикофинансовой деятельности компаний будет еще очень долго являться функциональной сферой бюджетирования.

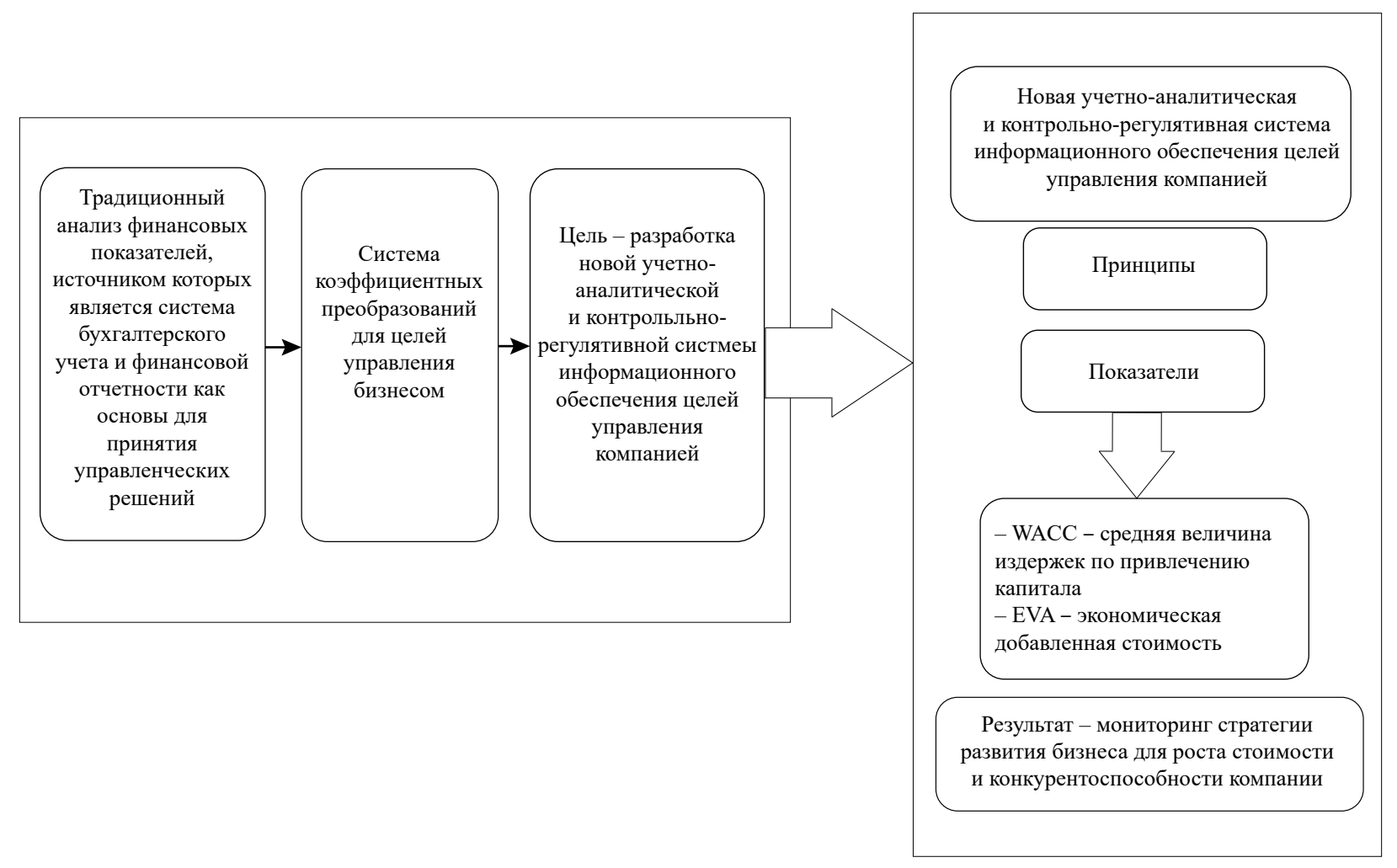

Составлено авторами по материалам исследования

Рис. 1. Информационное обеспечение целей управления бизнесом

Основным информационным источников для бюджетирования, ценообразования и оценки результативности всегда будет являться бухгалтерский учет, оперативные и отчетные показатели которого для целей управления будет подвергаться корректировочным модификациям, что отражает блок схема на рисунке 1.

Трансформация данных бухгалтерского учета и отчетности для целей управления стоимостью компании и ее бизнес-процессов представляет собой корректировку этих данных с помощью комплекса стратегически ориентированных коэффициентов. Наиболее просчитываемым коэффициентом считает коэффициент инфляционных изменений на ближайшие 2-3 года. От правильности такого учета зависят все остальные прогнозируемые показатели: объем предполагаемых финансово-хозяйственных договоров по стоимости и по участникам, прогнозируемые величины себестоимости единицы товарного выпуска, выручки, прибыли и т. д.

В реальной экономической жизни инфляция проявляется во всем многообразии своего экономического содержания. Методологи кейнсианского учения о факторах воспроизводства выделяют «инфляцию спроса» и «инфляцию издержек» как две взаимосвязанные составляющие инфляционного процесса [2]. От правильности выбора монетарными властями страны методов регулирования инфляции зависит и состояние экономик корпоративной сферы хозяйствования. Вместе с тем, руководство самих компаний может, ориентируясь на макроэкономические показатели, формировать свою финансовую политику на перспективу, закладывая в прогнозы корректировки по инфляционным индикаторам. 
При формировании стратегически ориентированных финансовых показателей базовое место занимает стоимость капитала компании. Для менеджмента компании важно максимально точно рассчитать предельную стоимость капитала для обеспечения экономического роста копании. При этом должны быть определены пределы привлечения капитала на финансовых рынках или из внутренних источников компании (капитализация прибыли).

Привлечение неограниченных объемов капитала при сохранении его прежней средневзвешенной цены в реальной хозяйственной практике невозможно, поскольку стоимость капитала возрастает по мере роста потребности в инвестициях. С наращиванием объема заемных средств возрастает и финансовый риск. Как правило, стоимость банковских кредитов (процентные ставки) постоянно растет, равно как и требуемый уровень доходности новых эмиссионных выпусков акций и облигаций. Следовательно, для регулирования финансовых рисков при формировании бюджета капитала необходимо определять его предельную стоимость, т. е. границу эффективности дополнительного привлечения капитала с позиций уровня WACC. Предельная стоимость капитала рассчитывается по формуле:

$$
M C C=(\triangle W A C C / \Delta K) \cdot 100 \%,
$$

где $\triangle W A C C$ - прирост средневзвешенной стоимости капитала; $\Delta K$ - прирост суммы капитала.

Пользуясь этой формулой, бухгалтер всегда может оценить эффективность различных бизнес-процессов, финансово-хозяйственных сделок и договоров, осуществление которых связано с дополнительным привлечением капитала. Для этого нужно сравнить предельную стоимость капитала с ожидаемым уровнем рентабельности по этим прогнозируемым объектам. Полученные данные сводят в специальный отчет «Показатели для целей управления бизнес-процессами», информация которого анализируют, а результаты используют для разработки финансовой стратегии, существенная часть которого составляет прогноз источников наращивания капитала.

В век информационных технологий и экономики знаний прогнозирование источников наращивания капитала осуществляется с помощью продвинутых информационных систем. Например, можно воспользоваться сервисом «Эксперт» от «СКБ Контур». Необходимые расчетные операции в этом сервисе уже включены в полный и подробный финансовый анализ компании. Получить все необходимые финансовые показатели просо - требуется только загрузить файл с бухгалтерской отчетностью в сервис. Получаемые через несколько секунд отчеты просты в понимании и наглядны не только для бухгалтеров, но и для других пользователей, например, для финансовых аналитиков банков, в которые обращаются компании за кредитами. Преимущество сервиса «Эксперт» и в том, что с его помощью можно анализировать возможность выездной налоговой проверки, получить показатель уровня кредитоспособности компании и величину рыночной стоимости бизнес-процессов и компании в целом. С помощью всех этих показателей также оценивается вероятность банкротства компании, что, безусловно, важно в условиях нестабильной экономики и постоянно растущей конкуренции на рынке услуг.

Результаты, достигаемые внедрением в компании учетно-контрольной системы информационноаналитического обеспечения целей управления рыночной стоимостью компании и ее бизнес-процессами, в которой системе сбалансированных показателей отводится центральное место, раскрывает блок-схема на рисунке 2.

Разработанная нами учетно-контрольная система информационно-аналитического обеспечения целей управления рыночной стоимостью компании и ее бизнес-процессами без проблем интегрируется с другими управленческими системами в режиме их параллельной автоматизации. Сюда же органично вписывается система бюджетного управления (планирование и анализа финансовых и других показателей), управление отношениями с клиентами (сбор и обработка показателей оценки клиентских перспектив), система менеджмента качества, инструменты оперативного бухгалтерского учета и контроля.

Современная глобализация экономических связей усиливает конкуренцию и предопределяет необходимость поиска методов разработки и принятия управленческих решений, позволяющих руководству российских экономических субъектов не только выдерживать конкурентный натиск со стороны глобальных рынков, но расширять производственные возможности компаний. 
Результаты функционирования системы сбалансированных показателей (ССП) в контуре учетно-контрольная система информационно-аналитического обеспечения

Рост эффективности управления за счет экономии затрат и рационализации функций руководства

При незначительном росте фонда оплаты труда увеличиваются базовые финансовые показатели

Повышается эффект отдачи эффективного труда за счет системы премирования персонала, «завязанной» на ССП

Высвобождается время на творческое осмысление результатов тактических действий

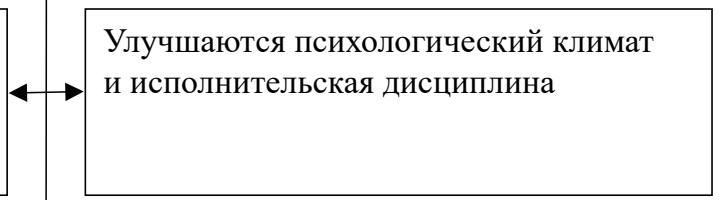

\begin{tabular}{|l|l|}
$\begin{array}{l}\text { Проводится углубленный внутренний } \\
\text { контроль за соответствием ССП } \\
\text { прогнозным индикаторам развития } \\
\begin{array}{l}\text { бизнес-процессов. Контроль позволяет } \\
\text { вносить коррективы в конкретные } \\
\text { бизнес-процессы }\end{array}\end{array} \mid \begin{array}{l}\text { Управление становится проактивным } \\
\text { за счет перенесения акцентов } \\
\text { руководства на реализацию рыночных } \\
\text { возможностей, а не разрешение текущих } \\
\text { проблемных ситуаций в компании }\end{array}$ \\
\end{tabular}

Составлено авторами по материалам исследования

Рис. 2. Содержание результативности функционирования системы сбалансированных показателей

Решению такой сверхзадачи существенно препятствуют типичные для российских компаний проблемы:

- недостаточная «прозрачность» процессов учета затрат, препятствующая выявлению подлинных причин их волатильности и применению новейших экономических технологий их оптимизации;

- все еще низкий уровень профессионализма персонала большинства компаний, владеющих новейшими экономическими технологиями оптимизации затрат и прибыли;

- отсутствие у многих компаний систем мотивации персонала на снижение уровня затрат и повышение эффективности финансово-хозяйственной деятельности и ответственности персонала за результаты труда;

- отсутствие высоко технологичных коммуникативных систем;

- недолжный уровень финансовой дисциплины и ответственности руководителей линейных подразделений;

- использование устаревших приемов формирования системы первичного документооборота.

- отсутствие системного и стратегически ориентированного планирования затрат, выручки и финансовых потоков;

- неразработанность систем формирования внутренней финансовой отчетности, затрудняющая консолидацию отчетных материалов в единое целое.

Формирование научно обоснованной системы учета для целей управления бизнес-процессами компании предполагает формализацию каждого из этих процессов.

С позиций управления важнейшим бизнес-процессом компании является движение денежных средств, поскольку без необходимого финансирования невозможно ни одно производство продукции, работ и услуг, а получение выручки предполагает ее распределение и организацию новых потоков движения денежных средств. 
Для этих целей необходима формализация финансовой модели компании, т. е. подробное описание денежных потоков между линейными подразделениями компании и центральным офисом «материнской» компании, с одной стороны, и между ними и контрагентами внешнего рынка, финансовой, налоговой, банковской, страховой, пенсионной системами. Поэтому важное место в финансовой модели компании отводится формализации ее платежной системы. Документирование и обработка финансовой, производственной информации представляет собой ничто иное как формализация учетно-контрольной систем.

Взаимосвязи всех формализованных систем воедино сводятся к созданию организационно-функциональной структуры управления компанией, информационной основой которой является интегрированный учет и управление качеством бизнес-процессов. Это предполагает в свою очередь описание Миссии основных структурных подразделений материнской компании, участвующих в бизнес-процессах, определение их функциональных обязанностей, моделирование вертикально-горизонтальных связей. На основании полученных моделей разрабатывают сводную модель организационно-функционального механизма управления компанией, которая встраивается в систему структурно-функциональных производственно-социальных, финансово-налоговых и других компетенций «материнской» компании.

Все это сложное построение процессов управления бизнес-процессов требует обширной и разнопрофильной информации. В основе системы информационного обеспечении целей управления бизнес-процессами компании и ее рыночной стоимостью находится модифицированная под цели управления система бухгалтерского учета. В настоящее время такая система именуется по-разному. Одни методологи управления определяют ее как управленческий учет, а другие - как контроллинг. Некоторые ученые полагают, что зарубежная модель контроллинга есть российская система организации и функционирования управленческого учета. Последнее, нами полностью отрицается, ибо такая постановка вопроса неверна в корне. Историческая практика управления бизнес-процессами дает ясное представление о том, что ни одна, даже самая уникальная, зарубежная управленческая модель не может иметь аналогов в отечественных реалиях в силу их крайней специфичности. Кардинальные отличия определяет, прежде всего, такой базовый фактор как собственность (формы, правовая защита, незыблемость и многое другое).

На наш взгляд, и понятие «контроллинг» и понятие «управленческий учет» не в полной мере адекватны для российских условий моделирования систем и механизмов управления бизнес-процессами и стоимостью компании как с позиций экономической теории, так и практики управления. Прежде всего, следует отметить, что понятие «контроллинг», пришедшее в Россию из зарубежной методологии управления, до настоящего времени не охарактеризовано как конкретный, ясный, непротиворечивый процесс управления затратами и прибылью компании, их соотношением в текущем периоде, а тем более в стратегическом плане. Опросы менеджеров компаний показывают, что для них понятие «контроллинг» сводится в лучшем случае к бюджетированию затрат и выручки, сопровождаемого контрольными процедурами. Большинство же менеджеров и бухгалтеров сводят смысл контроля только к оперативному внутреннему бухгалтерскому учету и контролю в традиционном понимании одного и другого.

Проведенные нами исследования систем управления бизнес-процессами в компаниях, специализирующихся на предоставлении услуг (консультационных, реинжиниринговых, маркетинговых) показывают постепенное развертывание в этих компаниях процессов документирования, органично сочетающих чисто бухгалтерскую информацию и комплекс модифицированной из бухгалтерских регистров и отчетности информации, которую запрашивают управленцы компании. Конфигурация и параметры такой новой информационной системы для целей управления бизнес-процессов определяются под потребности каждой компании в силу ее отраслевой специфики, места на рынке услуг и имеющегося потенциала в расчете на рост будущей стоимости. В итоге формируется учетноконтрольная система аналитического обеспечения целей управления бизнес-процессов и рыночной стоимость компании. Как правило, формирование такой системы основывается на целом комплексе рекомендаций менеджеров, на которых руководство возлагает этот процесс. В частности, необходимыми рекомендациями следует считать:

- правила выделения внутри компании Центров затрат, выручки, прибыли, инвестиций, формулирование основных принципов их функционирования (полномочия, обязанности и ответственность, мотивации). Отдельным документом может разрабатываться варианты построения организационно-функциональных структур этих Центров и их коммуникационные системы. Функционирование таких Центров определяет содержание информации для финансового учета, ведущегося в централизованной бухгалтерии компании; 
- методы учета затрат, определения финансовых результатов в рамках «внутрицентрового планирования» доходов, расходов и денежных потоков;

- сводный план мероприятий по внедрению предложенных рекомендаций для развития внутрикорпоративной учетно-контрольной система аналитического обеспечения целей управления бизнес-процессов и рыночной стоимость компании. К плану прилагается отдельным документом методика оценки экономического эффекта от внедрения предложений.

В сложном бизнесе предоставления различных видов услуг экономический эффект складывается из многих показателей, содержании которых будет раскрыто ниже. Общий же эффект заключается в достижении адекватности результатов функционирования смоделированной нами учетно-контрольной система информационно-аналитического обеспечения поставленных руководством компании целей управления бизнес-процессами и их рыночной стоимостью. Требование адекватности означает:

- полноту и своевременность выполнение всеми Центрами ответственности необходимых для достижения целей компании функций;

- ясность, комплексность, непротиворечивость, отсутствие дублирования горизонтально-вертикальных потоков информации, используемой руководством для разработки и принятия управленческих решений.

Существенное влияние на совокупный эффект оказывает также правильность структурирования организационно-функциональной структуры каждого Центра ответственности, определения его функций и подотчетности. Понятие «правильность» нами раскрывается как оптимальное распределение функций между подразделениями и сотрудниками внутри Центров, главное, чтобы отсутствовали дублирующие функции, а информация поступала своевременно и в полном, т. е. затребованном руководством объеме. Кроме того, «правильность» - это наличие «функциональных портретов» Центров ответственности: перечень должностей, требований к отдельным рабочим местам, ответственность за неисполнение обязанностей или их некачественное исполнение. Для этого составляются должностные инструкции, являющиеся важной и неотъемлемой частью системы управления. Должностная инструкция (описание рабочего места: задачи, подчиненность, права и обязанности, выполняемые функции, методы реализации функций, процедуры отчетности, процедуры работы с документами). При составлении должностных инструкций следует придерживаться принципа, основанного на описании функциональных обязанностей, а также организационных процедур деятельности сотрудника. Только в таком случае можно обеспечить повышение управляемости финансово-хозяйственной деятельностью компании и рост ее рыночной стоимости в перспективе устойчивого функционирования.

Ключевым этапом построения учетно-контрольной системы информационно-аналитического обеспечения целей управления бизнес-процессами и рыночной стоимостью компании является разработка документа под названием «Методика учета затрат и определения финансовых результатов (МУЗОФР)». Этот документ закладывает основу построения корпоративной учетно-контрольной системы. Такая методика должна включать:

- методы построения единой для всех центров ответственности классификации статей затрат;

- методики нормирования затрат для разделения затрат на экономически оправданные (полезные) и избыточные, а также - релевантные и неревантные;

- методики калькулирования затрат и формирования сводных показателей себестоимости по видам услуг, предоставляемых компаниям заказчикам по хозяйственным договорам;

- методика расчета финансового результата (прибыли) в разрезе центров ответственности, бизнеспроцессов и видов предоставляемых компанией услуг.

Bce вышеназванные методики до настоящего времени основываются на Activity Based Costing, Direct Costing и других методологических рекомендациях, апробированных отечественными бизнес-структурами.

Методология системы интегрированного учета получила свое развитие во многих рыночно развитых странах, в России она еще остается предметом научных дискуссий, и только в компаниях со стопроцентной долей иностранного капитала такая система постепенно адаптируется к практике. Российские методологи учета высказывают мнение, что адаптация системы интегрированного учета к российской условиям организации учетного процесса существенно ускорится с переходом на принципы международных стандартов финансовой отчетности. 
Библиографический список

1. Бодяко, А. В. Концепты «учет» и «бухгалтерский учет» как феномены осмысления целей хозяйствования // Вестник Университета. - 2017. - № 10. - С. 62-66.

2. Нуреев, Р. Инфляция: основные виды и методы регулирования // М. - Центр дистанционного образования «Элитариуем» [Электронный ресурс]. - Режим доступа: http://www.elitarium.ru/infljacija-spros-rost-ceny-proizvodstvo-izderzhki-tovaryjekonomika-zarabotnaja-plata-dengi-regulirovanie/(дата обращения: 25.04.2018).

3. Рогуленко, Т. М. Теоретический анализ категориального аппарата управленческого учета / Т. М. Рогуленко, В. В. Горлов // Российский экономический интернет-журнал. - 2016. - № 4. - С. 51.

4. Bodiako, A. V. et al. The goal setting of internal control in the system of project financing / A. V. Bodiako, S. V. Ponomareva, T. M. Rogulenko, M. Karp, E. Kirova, V. V. Gorlov, A. Burdina // International Journal of Economics and Financial Issues. 2016. - T. 6. - № 4. - C. 1 945-1 955.

5. Troshin, A.N. et al. Mechanism to analyze economic reliability of the innovational potential ofaircraft enterprises / A. N. Troshin, A. A. Burdina, N. V. Moskvicheva, E. N. Nikulina, E. V. Tarasova, T. M. Rogulenko // International Journal of Applied Business and Economic Research. - 2016. - T. 14. - № 14. - C. 747-765.

\section{References}

1. Bodyako A. V. Koncepty «uchet» $\mathrm{i}$ «buhgalterskij uchet» kak fenomeny osmysleniya celej hozyajstvovaniya [Concepts «accounting» and «accounting» as a phenomenon of understanding the goals of management] // Vestnik Universiteta, 2017, I. 10, pp. $62-66$.

2. Nureev R. Inflyaciya: osnovnye vidy i metody regulirovaniya. [Inflation: the main types and methods of regulation]. M. Centr distancionnogo obrazovaniya «EHlitariuem». Available at: http://www.elitarium.ru/infljacija-spros-rost-ceny-proizvodstvo-izderzhki-tovary-jekonomika-zarabotnaja-plata-dengi-regulirovanie/25.06.2012 g (accessed 07.06.2018).

3. Rogulenko T. M., Gorlov V. V. Teoreticheskij analiz kategorial'nogo apparata upravlencheskogo ucheta [Theoretical analysis of the categorical apparatus of management accounting] // Rossijskij ehkonomicheskij internet-zhurnal, 2016, I. 4, pp. 51.

4. Bodiako A. V. et al. The goal setting of internal control in the system of project financing / A. V. Bodiako, S. V. Ponomareva, T. M. Rogulenko, M. Karp, E. Kirova, V. V. Gorlov, A. Burdina // International Journal of Economics and Financial Issues, 2016, V. 6, I. 4, pp. 1 945-1 955.

5. Troshin A.N. et al. Mechanism to analyze economic reliability of the innovational potential ofaircraft enterprises / A. N. Troshin, A. A. Burdina, N. V. Moskvicheva, E. N. Nikulina, E. V. Tarasova, T. M. Rogulenko // International Journal of Applied Business and Economic Research, 2016, V. 14, I. 14, pp. 747-765. 